\title{
A Dual-Factor Approach to Exploring Wraparound Outcomes in Children with Serious Emotional Disturbance within Community-Based Mental Health Settings
}

\author{
Rebecca N. Thomson ${ }^{1}$, John S. Carlson ${ }^{1}$, Dylan S. T. Voris ${ }^{1}$, Millie Shepherd ${ }^{2} \&$ Kim Batsche-McKenzie ${ }^{2}$ \\ ${ }^{1}$ Counseling, Educational Psychology, and Special Education, Michigan State University, East Lansing, MI, \\ USA \\ ${ }^{2}$ Michigan Department of Health and Human Services, Division of Mental Health Services to Children and \\ Families, Lansing, MI, USA \\ Correspondence: John S. Carlson, Counseling, Educational Psychology, and Special Education, Michigan State \\ University, East Lansing, MI, USA. E-mail: carlsoj@msu.edu
}

Received: December 22, 2016

Accepted: January 11, 2017

Online Published: February 7, 2017

doi:10.5539/ijps.v9n1p107

URL: http://dx.doi.org/10.5539/ijps.v9n1p107

\begin{abstract}
Research has documented positive outcomes for youth who receive wraparound services; however, the specific mechanism for change has not yet been clarified. Data were collected from a sample of 253 youth with Serious Emotional Disturbance (SED) who completed wraparound services as a part of publically-funded community-based mental health services ( $58 \%$ male; 49\% Caucasian; mean age 12.25 years). Results indicated that both environmental and individual protective factors increased significantly and risky behaviors, including self-harm and aggressive behaviors, decreased significantly throughout youths' time in wraparound services. Improvements in protective factors and decreases in risk factors were significant predictors of clinically significant mental health improvement at exit from community-based wraparound services. Study findings highlight the utility and importance of a dual-factor approach to mental health assessment when implementing and evaluating wraparound services.
\end{abstract}

Keywords: protective factors, risky behavior, mental health, wraparound services, dual-factor approach, serious emotional disturbance

\section{Introduction}

Guided by a set of common principles (e.g., individualized, culturally-sensitive, team-based, collaboration, strengths-based, outcome-based; Bruns et al., 2010), wraparound is a mental health service-delivery approach that is utilized to coordinate care for youth with serious emotional disturbance (SED; Wery \& Cullinan, 2013) and their families (Chitiyo, 2014). Wraparound services are implemented within community-based mental health services as an alternative to costly out-of-home or non-community placements (Bruns et al., 2010). While there is no universally accepted manual for wraparound practices, Walker, Bruns, and the National Wraparound Initiative Advisory Group (2008) highlighted four phases of wraparound implementation: 1) Engagement and team preparation, 2) Initial plan development, 3) Implementation, and 4) Transition (for a description of each phase, see Walker et al., 2008). This practice model provides a foundation for wraparound practice across individuals, teams, and agencies (Walker et al., 2008).

Wraparound services have been linked with a number of positive outcomes, such as improved placement stability, school achievement (Suter \& Bruns, 2009), school attendance, family and peer relationships (Bruns, Rast, Peterson, Walker, \& Bosworth, 2006), and overall mental health functioning (Painter, 2012; Stambaugh et al., 2007). Though youth show improvements in a variety of domains throughout wraparound services, the evidence base for wraparound remains underdeveloped (Bruns, Pullmann, Sather, Brinson, \& Ramey, 2015; Chitiyo, 2014). Specific mechanisms for change need additional focus within the literature (Cox, Baker, \& Wong, 2010). 


\subsection{Mechanisms for Change}

Although the stages of implementation are structured, wraparound services are highly individualized (Bruns et al., 2010) creating challenges in identifying a specific mechanism for change (Cox et al., 2010). In an effort to refine theories of change, some have pinpointed specific principles (e.g., family voice and choice, team based, natural supports, collaboration, community based; Bruns, Walker, \& The National Wraparound Initiative Advisory Group, 2008) and activities (e.g., describing and prioritizing needs/goals, selecting strategies, assigning action steps, creating a crisis/safety plan; Walker et al., 2008) that may lead to positive outcomes for youth. However, these approaches have had limited success explaining improvements during wraparound.

Walker (2008) developed a model that provides guidance in understanding how wraparound services may lead to improved functioning. This model highlights two specific pathways for change, each driven by the foundational idea that the presence of protective factors enhances the probability of positive outcomes for youth and families (Fraser, Kirby, \& Smokowski, 2004). The first proposed pathway suggests that, "using the wraparound process to select and organize services and supports actually enhances the effectiveness of the chosen service/support strategies" (Walker, 2008, p. 5). Services and supports function as environmental protective factors (e.g., positive connections with caring adults, participation in extracurricular activities; Fraser et al., 2004; Wright \& Masten, 2005), and these positive interactions between youth and their surrounding systems (e.g., family, peers, school, community) help to stimulate positive youth development (Walker, 2015). While the first pathway focuses on environmental protective factors, the second emphasizes the role of individual protective factors, highlighting "wraparound's potential to increase family and youth resources and capacities related to planning, coping, and problem-solving" (Walker, 2008, p. 7). Specific individual protective factors may include social-emotional skills, a positive outlook on life, self-esteem, and other personal qualities (Fraser et al., 2004; Wright \& Masten, 2005). Activities central to the wraparound process allow youth the opportunity to practice and develop important individual protective factors, such as making decisions, setting goals, and developing solutions to problems.

The two pathways proposed by Walker (2008) link well to resilience theory, which suggests that the development of protective factors increases the likelihood of positive developmental outcomes by reducing one's risk for later challenges (Fraser et al., 2004). This dual-factor approach (i.e., a focus on both risk and protective factors) to mental health assessment and treatment (Greenspoon \& Saklofske, 2001; Suldo \& Shaffer, 2008) commonly reported within the field of community psychology (e.g., Ernestus \& Prelow, 2015; Monahan, Oesterle, Rhew, \& Hawkins, 2014) is often missing within wraparound outcome studies (Walker, 2015). Identifying reductions in risk factors and improvements in protective factors can help to further uncover the elusive mechanisms of change associated with wraparound services, which could help to further improve the training of wraparound facilitators (Walker \& Matarese, 2011).

\subsection{Promoting Protective Factors within Wraparound Services}

Measurement of protective factors (i.e., child and family strengths, relevant services and supports) is a key component of the wraparound process (McCammon, 2012). Walker (2004) found that while child and family strengths were mentioned in the vast majority of wraparound meetings, these discussions were not frequently acted upon. Similarly, teams often discussed the availability of community services, but rarely funded or facilitated access to these services (Walker, 2004). While the discussion of protective factors is central to the wraparound process, limited attention has been given to whether youth and families actually build new protective factors over time.

\subsubsection{Environmental Protective Factors}

Environmental protective factors typically include social support and opportunities for education or experiential learning (Fraser et al., 2004). Although wraparound services focus heavily on strengthening family and community relationships, previous evaluations have not shown clear evidence that wraparound is actually able to increase social support for youth and families (e.g., Clark, Lee, Prange, \& McDonald, 1996; Illback, Nelson, \& Sanders, 1998). Furthermore, it is unclear how an increase in social supports is connected to outcomes (e.g., functioning, placement permanency, restrictiveness of living situations) for youth who complete wraparound services (Cox, 2005). For instance, Cox and colleagues (2010) found that when there were more natural supports (e.g., siblings, parents, grandparents, friends) on the wraparound team, there was a greater likelihood of meeting treatment goals. However, Illback et al. (1998) found that support services were rarely provided to wraparound consumers and family satisfaction with sources of support did not change throughout the wraparound process. 


\subsubsection{Individual Protective Factors}

Individual protective factors include personal skills and abilities, such as academic skills, social-emotional skills, and coping skills (Fraser et al., 2004; Wright \& Masten, 2005). Previous research has used surveys and questionnaires to assess the presence of individual protective factors for children and families (McCammon, 2012). Painter (2012) assessed individual protective factors (e.g., self-confidence in one's abilities; ability to manage emotions) using the Behavioral and Emotional Rating Scale (BERS-2; Epstein, 2004) every six months throughout a two-year period of time in wraparound services. Findings revealed that parent-rated protective factors significantly increased after just six months in wraparound; however, youths' self-rated protective factors did not change over time (Painter, 2012). Protective factor data based on information from multiple sources (e.g., reports from wraparound facilitators based on information gathered from all team members) may help to further our understanding of wraparound outcomes.

Another study investigated both environmental and individual protective factors for youth who complete wraparound services. Weiner, Leon, and Stiehl (2011) collected information about child protective factors (e.g., positive relationships with family, positive relationships with peers, coping skills) using the Child and Adolescent Needs and Strengths tool (CANS; Lyons, 2009). Results revealed that a higher score for child strengths predicted greater placement stability (Weiner et al., 2011). While a major goal of wraparound services is for youth to maintain stable community placements (Winters \& Metz, 2009), it is not clear whether these protective factors were related to improvements in overall functioning to the point where community services were no longer needed.

Research has not clearly articulated which specific protective factors are developed throughout the wraparound process, or how they impact child and family well-being (McCammon, 2012), though wraparound services are often mentioned as a way to increase protective factors (Morrison, Brown, D'Incau, O'Farrell, \& Furlong, 2006). The theory connecting the use of strength-based interventions to enhance well-being is empirically supported (Wood, Linley, Maltby, Kashdan, \& Hurling, 2011), but has yet to be investigated within the wraparound population.

\subsection{Decreasing Risk Factors within Wraparound Services}

Overall mental health functioning improves when protective factors increase and risk factors decrease (Greenspoon \& Saklofske, 2001). Therefore, while wraparound services must be strengths-based (Chitiyo, 2014), it is also essential to measure the reduction of negative indicators associated with impairment in functioning. A common negative indicator among youth with SED is risky behavior (e.g., harm to self or others, substance use, criminal offenses), which has been negatively associated with health and well-being (e.g., Cleverly, Szatmari, Vaillancourt, Boyle, \& Lipman, 2012; Green, Zebrak, Robertson, Fothergill, \& Ensminger, 2012). Although it is clear that youth with SED engage in high levels of risky behavior (Epstein, Cullinan, Quinn, \& Cumblad, 1994), very few studies have investigated whether risky behaviors decline throughout youths' time in wraparound services.

\subsubsection{Harm to Self or Others}

Impairments caused by SED can increase youths' risk for hurting themselves or others (Erickson, 2011). Only a few studies to date have investigated changes in aggressive behaviors toward others throughout wraparound services. One randomized, controlled trial of 141 delinquent youth found that those receiving wraparound were less assaultive at the completion of services than youth who received conventional services (Carney \& Buttell, 2003). Another case study involving four adolescents by Myaard and colleagues (2000) also indicated reductions in physical aggression following wraparound services. Changes in self-harm behavior following wraparound services have yet to be reported.

\subsubsection{Substance Abuse}

Results from the National Adolescent and Child Treatment Study (NACTS) indicated that substance use disorders were the most commonly associated psychiatric condition among 17- to 25-year-olds previously diagnosed with SED (Davis \& Stoep, 1997). However, studies investigating wraparound services have not investigated changes in youth substance use behaviors (Burns, Schoenwald, Burchard, Faw, \& Santos, 2000). Thus, questions remain about whether wraparound services may reduce the use of substances (e.g., drugs, alcohol). 


\subsubsection{Criminal Offenses}

The arrest rate for youth with SED is higher than for youth in any other disability category (Wagner \& Newman, 2012). Data from 248 young adults with SED revealed that approximately 61 percent had been arrested and 44 percent had been on probation or parole (Wagner \& Newman, 2012). Once youth with SED become involved with the juvenile court systems, it is unclear whether wraparound services are able to reduce the likelihood of future criminal offenses. For example, Carney and Buttell (2003) failed to identify differences in arrest or incarceration rates between youth receiving wraparound services and youth receiving conventional juvenile court services. In contrast, Pullmann and colleagues (2006) did find that youth who completed wraparound services were less likely to commit criminal offenses when compared to youth who received existing community-based services.

\subsection{Purpose and Research Questions}

The purpose of this study was to explore wraparound outcomes from the perspective of a dual-factor approach to mental health (Greenspoon \& Saklofske, 2001). First, Walker's (2008) assertion that the development of protective factors (i.e., positive indicators) may be a mechanism for change throughout wraparound services was empirically investigated. Second, changes in risky behaviors (i.e., negative indicators) from wraparound entry to exit were examined. The study also explored how protective factors (i.e., environmental, individual) and risky behaviors (i.e., harm to self or others, substance abuse, criminal offenses) relate to overall mental health functioning outcomes. The following research questions were investigated:

1) How do protective factors change from the initiation of community-based wraparound services to a child's exit from wraparound?

2) How do risky behaviors change from the initiation of community-based wraparound services to a child's exit from wraparound?

3) Does an increase in protective factors inversely correlate with decreases in risky behavior from entry into community-based wraparound services to exit?

4) What is the association between the presence of protective factors/risky behaviors and a child's level of overall mental health functioning at exit from community-based wraparound services?

\section{Methods}

\subsection{Participants}

This study included a sample of 253 youth with SED from 30 community-based wraparound programs across the state of Michigan. The study sample was identified from an extant data set containing 597 youth who are or had been receiving wraparound services based on three inclusion criteria: 1) participants had valid data for level of functioning (as measured by the Child and Adolescent Functional Assessment Scale (CAFAS; Hodges, 1990)), all protective factor variables, and all risky behavior variables, 2) participants received wraparound services for at least three months, and 3) wraparound facilitators indicated that participants met their treatment goals. This method of limiting study participants to only those who had specific data available and those who met certain conditions is similar to the methods found within the existing wraparound literature (e.g., Effland, Walton, \& McIntyre, 2011).

On average, participants received wraparound services for 10.74 months $(S D=5.61)$. Participants ranged in age from 7 to 18 years $(M=12.25$ years, $S D=2.92)$, and more than half were male $(58 \%)$. Participants represented a variety of racial/ethnic groups, including Caucasian (49\%), African American (30\%), Mixed (11\%), Hispanic/Latino (6\%), Other (2\%), and Not Reported (2\%). Youth received a variety of services throughout wraparound, and services varied based upon individual participant and family needs. The following three services were provided most frequently: intensive home-based therapy (Entry: 59\%; Exit: 57\%), psychiatric services (evaluation/medication monitoring; Entry: 53\%; Exit: 56\%), and outpatient therapy (Entry: 37\%; Exit: $43 \%)$.

To further describe the participant sample, CAFAS subscale scores were used to identify youths' most significant area of impairment. At entry into Wraparound services, youth were categorized into one of seven CAFAS tiers (in order from most severe to least severe impairment; Hodges, Xue, \& Wotring, 2004): 1) Thought Problems $(N=26 ; 10 \%), 2)$ Maladaptive Substance Use $(N=8 ; 3 \%), 3)$ Self-Harmful Potential $(N=74 ; 29 \%), 4)$ Delinquent Behavior $(N=47 ; 19 \%), 5)$ Behavior Problems with Moderate Mood Disturbance $(N=81 ; 32 \%), 6)$ Behavior Problems $(N=13 ; 5 \%)$, and 7) Moderate Mood/Mild Behavioral Problems $(N=0 ; 0 \%)$. Four youth $(2 \%)$ did not qualify for any of the tiers. 


\subsection{Measures}

Wraparound facilitators collected data using the Family Status Report (FSR), which includes questions about residential living status, housing, education, strengths, level of functioning, services, and team membership. Each dependent variable was assessed with a different section of the FSR, as outlined below.

\subsubsection{Protective Factors}

Protective factors were evaluated with the Strengths Assessment section of the FSR, a 17-item questionnaire focused on environmental and individual protective factors. Environmental protective factors included: 1) opportunities to participate in interests/hobbies, 2) having supports to achieve goals, 3) positive connections in the home, 4) positive connections in the community, 5) having adults to ask for help when needed, 6) socialization with peers, 7) participation in wraparound team meetings, and 8) taking family strengths into account in the wraparound plan. Individual protective factors included: 1) expression of general interests/hobbies, 2) active involvement in programs to exhibit interests/hobbies, 3) expression of personal goals, 4) taking action steps to achieve goals, 5) presenting with generally good health, 6) ability to express needs/desires, 7) ability to develop solutions to problems, 8) comfort engaging with others in social settings, and 9) coping skills needed to manage stressful situations. Facilitators marked Yes or No to indicate whether there was evidence of each protective factor for the child. No psychometric data has been published on this measure to date.

\subsubsection{Risky Behaviors}

Risky behaviors were assessed with the Safety Indicators section of the FSR, a 7-item questionnaire that assesses three categories of risky behaviors: 1) Harm to Self or Others, 2) Substance Use, and 3) Criminal Offenses. Harm to Self or Others includes three items: a) "physically hurt themselves on purpose", b) "made verbal statements about hurting themselves or others", and c) "physically hurt other people on purpose". Substance Use includes two items: a) "used drugs", and b) "used alcohol". Criminal Offenses includes two items: a) "charged with a crime(s) during this quarter", and b) "had any probation violations". The questions related to Harm to Self or Others and Substance Use utilize a 5-point Likert-type scale assessing the frequency of each behavior $(1=$ Has Not Occurred to $5=10+$ times). For the questions related to criminal offenses, facilitators marked Yes or No to indicate whether youth had any criminal charges or probation violations. No psychometric data has been published on this measure to date.

\subsubsection{Overall Functioning}

Level of functioning data was gathered using the CAFAS (Hodges, 1990). This standardized, validated tool, is completed by the youth's therapist and completion is ensured by wraparound facilitators. The CAFAS measures youths' current functioning across eight life domains: School, Home, Community, Behavior Toward Others, Moods/Emotions, Self-Harm, Substance Use, and Thinking. Each domain is rated using a 4-level scale, where a score of 30 reflects severe impairment, 20 moderate impairment, 10 mild impairment, and 0 minimal or no impairment. Scores for each domain are added together to form a total CAFAS score, ranging from 0 to 240. Higher CAFAS scores indicate more impaired functioning, and a decrease in CAFAS scores over time indicates an improvement in youths' functioning. Clinically significant improvements in functioning are denoted by an improvement of 20 or more points on the CAFAS. The CAFAS has strong interrater reliability (.74-.99) and adequate internal consistency (.63-.68; Hodges \& Wong, 1996). The CAFAS has also been strongly correlated with the Children's Global Assessment Scale (CGAS; Shaffer et al., 1983; $r=-0.72--0.91$ ) and moderately correlated with the Child Behavior Checklist (CBCL; Achenbach, 1991; $r=0.42-0.49$ ). Furthermore, CAFAS scores have been found to predict restrictiveness of living environment, cost of services, and number of services for youth in systems of care (Hodges \& Wong, 1997).

\subsection{Procedures}

Therapists in coordination with wraparound facilitators completed the FSR upon a child's entry into wraparound services and quarterly through a child's exit from services. Facilitators then entered de-identified FSR data into an online database (REDCap; Harris et al., 2009), where researchers accessed the information for analysis. To provide evidence that the wraparound process was completed as intended, fidelity surveys were gathered by wraparound facilitators, parents, team members, and youth six-months after the onset of wraparound services. Fidelity surveys included 25 items rated on a 5 -point Likert-type scale $(0=$ No to $4=$ Yes $)$, addressing each of the thirteen wraparound principles outlined by the state of Michigan (Michigan Department of Community Health, 2007). The total fidelity score ranges from 0 (indicating very low fidelity) to 100 (indicating very high fidelity). The overall average response was 68.73 , which means that overall fidelity of the wraparound process 
was at approximately $69 \%$. Fidelity scores did not differ significantly between the 30 wraparound programs $(F$ $[24]=1.04, p=.424)$, indicating that service provision was generally uniform.

The university's Institutional Review Board (IRB) and the state agency's Human Subjects Review Committee determined that this project met criteria for exempt research, given that researchers collected and analyzed existing data in such a manner that subjects could not be identified. All participants provide informed consent for engagement in wraparound services and the use of the de-identified data for evaluation purposes.

\subsection{Data Analyses}

Data were analyzed using the Statistical Package for Social Sciences (SPSS). To examine the first two research questions (change in protective/risk factors), the percentage of youth with each factor present was calculated at the entry and exit time points. Likert values were converted to binary values (i.e., did engage [1] or did not engage [0] in the risky behavior) for analysis. To determine significant differences, the McNemar Chi-Square test (which is appropriate for within-subject designs) was used. Additionally, items from the Strengths Assessment section of the FSR were categorized into environmental and individual protective factors. The numbers of environmental, individual, and total protective factors were computed at the entry and exit time points. For each of the three categories of risky behavior (Harm to Self or Others, Substance Use, Criminal Offenses), the number of risky behaviors in which youth engaged was totaled for the entry and exit time points. Paired samples t-tests were used to determine significant differences across time. Cohen's effect size values were computed to interpret practical significance.

To examine the third research question (relationship between risk and protective factors), the changes in protective factors and risky behaviors were calculated from wraparound entry to exit. Next, a bivariate correlation was used to explore a potential association between the two change variables. To examine the fourth research question (association between protective/risk factors and mental health functioning), a dichotomous variable was created to represent clinically significant improvements in CAFAS scores from the entry to the exit time point (a decrease in 20 points or more). A series of binary logistic regression analyses was used to assess the potential of various predictors on this outcome (i.e., clinically significant improvement). Predictors included: a) protective factors at exit (total, environmental, and individual), b) risky behaviors at exit (total, harm to self or others, substance use, and criminal offenses), c) change in number of protective factors from entry to exit, and d) change in number of risky behaviors from entry to exit.

\section{Results}

\subsection{Protective Factors}

Table 1 displays the percentage of youth with each protective factor at the entry and exit time points. McNemar Chi-Square tests reveal that the percentage of youth with each protective factor (except for positive connections at home) increased significantly from wraparound entry to exit. On average, the percentage of youth with individual protective factors increased more over time than the percentage of youth with environmental protective factors. On average, the percentages of youth with individual protective factors grew by 17 percentage points, while the percentages of youth with environmental protective factors grew by 8 percentage points. The percentages of youth with coping skills, the ability to develop solutions to problems, and those taking steps to achieve their goals increased the most from entry to exit.

Table 1. Percentage of youth with protective factors at wraparound entry and exit

\begin{tabular}{llll}
\hline Protective Factors & Entry & Exit & $\%$ Change \\
\hline Environmental & & & \\
Opportunities to engage in interests/hobbies & $84 \%$ & $94 \%$ & $+10^{* * *}$ \\
Has supports needed to achieve goals & $90 \%$ & $96 \%$ & $+6^{* *}$ \\
Positive connections at home & $91 \%$ & $95 \%$ & +4 \\
Positive connections in the community & $73 \%$ & $90 \%$ & $+17^{* * *}$ \\
Has adults to ask for help when needed & $97 \%$ & $100 \%$ & $+3^{*}$ \\
Socializes with peers & $76 \%$ & $91 \%$ & $+15^{* * *}$ \\
Participates in wraparound meetings & $85 \%$ & $93 \%$ & $+8^{* *}$ \\
\hline
\end{tabular}


Family strengths taken into account in wraparound plan

$\begin{array}{lll}98 \% & 100 \% & +2 * \\ & & \\ 93 \% & 97 \% & +4 * \\ 55 \% & 68 \% & +13 * * \\ 71 \% & 85 \% & +14 * * * \\ 56 \% & 79 \% & +23 * * * \\ 95 \% & 99 \% & +4 * \\ 87 \% & 96 \% & +9 * * * \\ 54 \% & 81 \% & +27 * * * \\ 68 \% & 90 \% & +22 * * * \\ 31 \% & 72 \% & +41 * * *\end{array}$

$* \mathrm{p} \leq .05, * * \mathrm{p} \leq .01, * * * \mathrm{p} \leq .001$.

At entry into wraparound services, youth had an average of $6.92(S D=1.34)$ environmental protective factors and $6.09(S D=2.07)$ individual protective factors. At exit from wraparound services, youth had an average of $7.59(S D=.88)$ environmental protective factors and $7.68(S D=1.67)$ individual protective factors. Paired samples t-tests revealed that both environmental and individual protective factors increased significantly from entry to exit, $t(252)=7.46, p<.001$ and $t(252)=11.54, p<.001$, respectively. Cohen's effect size value for the change in environmental protective factors $(d=.59)$ suggested moderate practical significance. Cohen's effect size value for the change in individual protective factors $(d=.85)$ suggested large practical significance. Both types of protective factors were added to get a total number of protective factors at the entry and exit time points. Youth had significantly more protective factors in total at the exit time point $(M=15.26, S D=2.25)$ than at the entry time point $(M=13.02, S D=3.04), t(252)=11.35, p<.001$. Cohen's effect size value $(d=.84)$ suggested large practical significance.

\subsection{Risky Behaviors}

Table 2 presents the percentage of youth who engaged in risky behaviors at the entry and exit time points. McNemar Chi-Square tests show that the percentage of youth who engaged in four out of the seven risky behaviors (i.e., physically hurt themselves on purpose, made verbal statements about hurting themselves or others, physically hurt other people on purpose, probation violations) decreased significantly from the entry time point to the exit time point. On average, the percentage of youth who engaged in harm to self or others decreased the most over time, as compared with the change in percentage of youth who engaged in substance use or criminal offenses. On average, the percentage of youth who engaged in harm to self or others decreased by 19 percentage points, while the percentage of youth who engaged in substance use and criminal offenses decreased by 2 and 4 percentage points, respectively. The percentages of youth who physically hurt others on purpose and who made verbal statements about hurting themselves or others decreased the most over time.

Table 2. Percentage of youth who engaged in risky behaviors at wraparound entry and exit

\begin{tabular}{llll}
\hline Risky Behaviors & Entry & Exit & $\%$ Change \\
\hline Harm to Self or Others & & & \\
$\quad$ Physically hurt themselves on purpose & $21 \%$ & $10 \%$ & $-11^{* * *}$ \\
$\quad \begin{array}{l}\text { Make verbal statements about hurting themselves } \\
\text { or others }\end{array}$ & $43 \%$ & $22 \%$ & $-21^{* * *}$ \\
$\quad \begin{array}{l}\text { Physically hurt other people on purpose } \\
\text { Substance Use }\end{array}$ & $39 \%$ & $15 \%$ & $-24^{* * *}$ \\
$\quad$ & & & \\
$\quad$ Used drugs & $5 \%$ & $4 \%$ & -1 \\
\hline
\end{tabular}


Used alcohol

Criminal Offenses

\begin{tabular}{|c|c|c|c|}
\hline Charged with a crime & $8 \%$ & $4 \%$ & -4 \\
\hline Probation violations & $6 \%$ & $2 \%$ & $-4^{*}$ \\
\hline
\end{tabular}

$4 \% \quad 2 \% \quad-2$

$-2$

$* \mathrm{p} \leq .05, * * \mathrm{p} \leq .01, * * * \mathrm{p} \leq .001$.

Youth engaged in significantly more harmful behaviors at wraparound entry $(M=1.03 ; S D=1.05)$ than at wraparound exit $(M=.47 ; S D=.78), t(252)=8.37, p<.001$. Cohen's effect size value $(d=.61)$ suggested moderate practical significance. Youth also engaged in significantly more criminal offenses at wraparound entry $(M=.14 ; S D=.42)$ than at wraparound exit $(M=.06 ; S D=.26), t(252)=2.57, p=.011$. Cohen's effect size value $(d=.23)$ suggested small practical significance. There was not a significant change in the number of substance use behaviors over time. Risky behaviors in all three categories were added to get a total number of risky behaviors at the entry and exit time points. Youth engaged in significantly more risky behaviors in total at wraparound entry $(M=1.26 ; S D=1.18)$ than at wraparound exit $(M=.60 ; S D=.88), t(252)=8.39, p<.001$. Cohen's effect size value $(d=.63)$ suggested moderate practical significance.

\subsection{Correlation between Protective Factors and Risky Behaviors}

Bivariate correlation revealed a significant, negative, though weak, correlation between changes in protective factors over time and changes in risky behaviors, $r=-.19, p=.003$. This indicates that a greater increase in protective factors throughout wraparound services was associated with a greater decrease in risky behaviors. Further analysis indicates that only changes in individual protective factors were significantly correlated with changes in total risky behaviors, $r=-.20, p=.001$ (changes in environmental protective factors were not significantly correlated with changes in risky behaviors; see Table 3 ).

Changes in harmful behaviors were significantly correlated with changes in total protective factors $(r=-.24, p$ $<.001)$, as well as with changes in both environmental and individual protective factors $(r=-.17, p=.009$ and $r$ $=-.24, p<.001$, respectively). The negative correlation indicates that a greater increase in protective factors throughout wraparound services was linked with a greater decrease in harm to self or others. Changes in substance use and criminal offenses were not significantly correlated with changes in total, environmental, or individual protective factors (see Table 3).

Table 3. Correlations between changes in protective factors and risky behaviors

\begin{tabular}{clrl}
\hline & Change in Total Protective Factors & Environmental & Individual \\
\hline Change in Risky Behaviors & $r=-.187^{* *}$ & $r=-.108$ & $r=-.201^{* * *}$ \\
Harm to Self or Others & $r=-.241^{* * *}$ & $r=-.165^{* *}$ & $r=-.241^{* * *}$ \\
Substance Use & $r=-.005$ & $r=.000$ & $r=-.006$ \\
Criminal Offenses & $r=.046$ & $r=.082$ & $r=.013$
\end{tabular}

$* \mathrm{p} \leq .05, * * \mathrm{p} \leq .01, * * * \mathrm{p} \leq .001$

\subsection{Overall Mental Health Functioning}

Analyses indicated that $70 \%$ of youth $(N=177)$ attained clinically significant improvements in mental health functioning (a decrease of 20 points or more in CAFAS scores from wraparound entry to exit; Hodges, 1990). The results of binary logistic regression analyses indicate that the number of protective factors at the exit time point significantly predicted clinically significant improvement in functioning $(b=.21, p=.001)$. Both environmental and individual protective factors at wraparound exit significantly contributed to the prediction of clinically significant improvement in functioning $(b=.39, p=.009$ and $b=.27, p=.001$, respectively). 
Furthermore, the change in overall protective factors from wraparound entry to exit significantly predicted clinically significant improvement in functioning $(b=.16, p=.001$; see Table 4$)$.

Table 4. Logistic regression analysis of predictors of clinically significant improvement in functioning

\begin{tabular}{|c|c|c|c|}
\hline Variable & $b$ & $S E(b)$ & Odds Ratio \\
\hline Total Protective Factors at Exit & .206 & .060 & $1.229 * * *$ \\
\hline Environmental & .389 & .149 & $1.476^{* *}$ \\
\hline Individual & .266 & .081 & $1.305^{* * *}$ \\
\hline Total Risky Behaviors at Exit & -.401 & .151 & $.670 * *$ \\
\hline Harm to Self or Others & -.408 & .169 & $.665^{*}$ \\
\hline Substance Use & -.048 & .495 & .953 \\
\hline Criminal Offenses & -.805 & .495 & .447 \\
\hline Change in Protective Factors from Entry to Exit & .159 & .049 & $1.172 * * *$ \\
\hline Change in Risky Behaviors from Entry to Exit & -.526 & .128 & $.591 * * *$ \\
\hline
\end{tabular}

${ }^{*} \mathrm{p} \leq .05,{ }^{* *} \mathrm{p} \leq .01,{ }^{* * * \mathrm{p}} \leq .001$.

Binary logistic regression analyses indicated that total risky behaviors at exit from wraparound services significantly predicted clinically significant mental health improvements $(b=-.40, p=.008)$. However, Harm to Self or Others was the only category of risky behaviors that significantly predicted this outcome $(b=-.41, p$ $=.016$ ). Additionally, the change in risky behaviors from entry to exit was a significant contributor to the prediction of clinically significant improvement in functioning $(b=-.53, p<.001$; see Table 4$)$.

Odds ratios were explored for all significant predictors. An odds ratio of 1 indicates that the predictor variable does not influence the likelihood of the outcome (i.e., clinically significant improvement in functioning). An odds ratio greater than 1 indicates that the outcome is more probable for youth with an identified score on the predictor variable, and an odds ratio lower than 1 indicates that the outcome is less probable. Data show that youth with a higher number of total protective factors at the exit time point had a greater likelihood of attaining clinically significant improvements in functioning $(O R=1.23)$. This was true for both environmental $(O R=1.48)$ and individual protective factors $(O R=1.31)$. Furthermore, a greater increase in protective factors increased the likelihood that youth would attain clinically significant improvements in overall mental health $(O R=1.17)$.

Consistent with expectations, youth who displayed more risky behaviors at exit from wraparound services were less likely to have clinically significant mental health improvements $(O R=.67)$. In particular, more harmful behaviors were associated with a decreased likelihood for positive outcomes at exit from wraparound services $(O R=.67)$. Overall, a greater increase in risky behaviors over time decreased the likelihood that youth would attain clinically significant improvement in functioning $(O R=.59)$.

\section{Discussion}

The present study highlights the importance of considering a dual-factor approach to mental health (Greenspoon \& Saklofske, 2001) when examining outcomes associated with community-based wraparound services. Data from this study support a link between improvements in overall mental health functioning and both positive (e.g., protective factors) and negative indicators (e.g., risky behaviors) among youth with SED who complete wraparound services.

Participants demonstrated increases in protective factors throughout their experience in wraparound services. Analyses revealed that the percentage of youth with protective factors increased significantly from the entry to the exit time point. Furthermore, the number of environmental, individual, and total protective factors all increased significantly over time. These findings provide empirical support for Walker's (2008) two proposed pathways for change throughout wraparound. Specifically, wraparound services appear to help enhance the effectiveness of relevant services and supports in the child and family's lives (i.e., environmental protective 
factors) and these services appear to contribute to an increase in child and family strengths (i.e., individual protective factors).

While both environmental and individual protective factors increased significantly from wraparound entry to exit, changes in individual protective factors were more substantial. Since youth began wraparound services with more environmental protective factors in place (on average), it may be that there was less room for growth. It may also be that wraparound teams focused more heavily on building individual strengths, versus environmental protective factors. Walker (2004) found that wraparound teams rarely provided concrete resources or steps to help youth and families access available services (i.e., environmental protective factors), and Walker (2015) suggests that larger contextual changes may be necessary to expand access to services.

As hypothesized, improvements in protective factors during wraparound predicted clinically significant improvement in mental health functioning. This aligns with Cox et al.'s (2010) and Weiner et al.'s (2011) findings that natural supports, community resources, and child strengths were influential in leading to positive outcomes for youth in wraparound. Results provide further evidence for the theory that focusing on an individual's strengths is connected to enhanced well-being (Wood et al., 2011), and adds further empirical support for using a strengths-based approach within community-based mental health services (Bruns et al., 2010).

By using a dual-factor approach to measuring wraparound outcomes, study results further add to the literature by demonstrating that youth who complete wraparound services engage in less self-harmful behavior over time. In addition, decreases in youths' aggressive behavior toward others (i.e., made verbal statements about hurting themselves or others, physically hurt people on purpose) substantially declined, adding further support for the impact of wraparound services in reducing externalizing behaviors (Myaard et al., 2000; Carney \& Buttell, 2003). Probation violations decreased significantly for youth in the present study, but criminal charges did not. The discrepancy between informal (i.e., facilitator-reported) and formal (i.e., criminal charges) sources of data is similar to what was found by Carney and Buttell (2003), and, therefore, future research may seek to explore this difference directly. Substance use did not decrease significantly from wraparound entry to exit, though it is important to note that very few youth in this sample were reported to be using substances initially, which makes it difficult to observe significant reductions in use. Given that very few studies have investigated substance use for youth who complete wraparound services (Burns et al., 2000), further research is needed.

A strong connection between negative indicators (i.e., risky behaviors) and overall mental health was found. Fewer risky behaviors at wraparound exit (as well as a greater decrease in risky behaviors from entry to exit) predicted clinically significant improvements in mental health functioning. This aligns well with previous research documenting a negative association between risky behaviors and well-being (e.g., Cleverly et al., 2012; Green et al., 2012). In particular, Harm to Self or Others was the only category of risky behaviors that was found to significantly predict clinically significant improvements in mental health functioning. This finding makes intuitive sense given that considerable evidence supports the impact of wraparound services on reducing physical aggression (e.g., Carney \& Buttell, 2003; Myaard et al., 2000) and behavioral problems (e.g., Stambaugh et al., 2007), when compared to reductions in substance use or criminal offenses (e.g., Burns et al., 2000; Carney \& Buttell, 2003).

Study findings indicated an inverse relationship between protective factors and risky behaviors. Increases in total protective factors were correlated with decreases in total risky behaviors over time. However, more specific analyses revealed that only changes in individual protective factors were linked to changes in total risky behaviors. Given these results, it appears that individual factors (e.g., coping skills, problem-solving) may have more of a protective effect against participation in risky behaviors. This finding is consistent with Greenbaum and colleagues' (1996) assertion that the development of adaptive functioning skills may influence youth to choose healthy, adaptive behaviors. The results of the present study point to the need for building individual protective factors throughout wraparound services and the importance of measuring both protective and risk factors to make data-based decisions about the impact of service delivery efforts.

\section{Limitations}

Several limitations must be considered in the context of the present study's methods and results. First, generalizability of study findings to other wraparound programs or participants is not possible given the lack of a control group and limitations associated with studying a subset of participants who fully completed wraparound services. Second, our sample presents additional challenges to generalization of study findings given that it only included children and families in the public mental health system, Prepaid Inpatient Health Programs (PIHPs), and Community Mental Health Service Providers (CMHSPs) within one state. The demographic characteristics 
of our sample (58\% male; $49 \%$ Caucasian) and the mental health challenges present at service onset, as reflected in CAFAS tier data, too may differ substantially from other wraparound programs and cautious interpretation of study findings is essential. Finally, although facilitators completed FSRs with direct input from team members (e.g., parents, youth), future research should incorporate independent parent-report and youth self-report measures in order to corroborate and verify facilitator reports via a multi-informant approach.

\section{Conclusions}

The present study provides empirical evidence for the use of Walker's (2008) two pathways as mechanisms of change in wraparound services. Both environmental and individual protective factors increased throughout wraparound services, and both were significantly associated with positive mental health outcomes. Using this theoretical framework, wraparound supervisors should continue to emphasize the development of protective factors for youth and families through training and coaching efforts. It is essential that wraparound facilitators have a clear understanding of how to help youth and families build strengths, assist in securing services and supports, and work to retain children in services through completion of wraparound goals. Joint trainings involving child welfare and mental health practitioners can encourage the use of evidence-based assessment and early intervention/prevention strategies (Kerns et al., 2014).

Evaluating wraparound services from the perspective of a dual-factor approach to community-based mental health services (e.g., Ernestus \& Prelow, 2015; Monahan, Oesterle, Rhew, \& Hawkins, 2014) is essential. In the present study, the reduction of risky behaviors over time was related to positive mental health outcomes; therefore, although wraparound services are strengths-based (Chitiyo, 2014), it is important for facilitators to also focus on decreasing risk factors. Given that substance use and criminal offenses did not change as much over time as harmful behaviors, it would be interesting to determine whether wraparound outcomes improve even further with an increased focus of service delivery addressing these areas. It is recommended that training and coaching efforts highlight the importance of targeting risk factors, especially those related to harming oneself or others.

\section{References}

Achenbach, T. M. (1991). Manual for the Child Behavior Checklist 4-18 and 1991 profile. Burlington, VT: University of Vermont, Department of Psychiatry.

Bronfenbrenner, U. (1994). Ecological models of human development. International Encyclopedia of Education, 3, 1643-1647.

Bruns, E. J., Pullmann, M. D., Sather, A., Brinson, R. D., \& Ramey, M. (2015). Effectiveness of wraparound versus case management for children and adolescents: Results of a randomized study. Administration and Policy in Mental Health and Mental Health Services Research, 42, 309-322. https://doi.org/10.1007/s10488-014-0571-3

Bruns, E. J., Rast, J., Peterson, C., Walker, J., \& Bosworth, J. (2006). Spreadsheets, service providers, and the statehouse: Using data and the wraparound process to reform systems for children and families. American Journal of Community Psychology, 38, 201-212. https://doi.org/10.1007/s10464-006-9074-z

Bruns, E. J., Walker, J. S., \& The National Wraparound Initiative Advisory Group. (2008). Ten principles of the wraparound process. In E. J. Bruns, \& J. S. Walker (Eds.), The resource guide to wraparound. Portland, OR: National Wraparound Initiative, Research and Training Center for Family Support and Children's Mental Health.

Bruns, E. J., Walker, J. S., Zabel, M., Matarese, M., Estep, K., Harburger, D., ... Pires, S. A. (2010). Intervening in the lives of youth with complex behavioral health challenges and their families: The role of the wraparound process. American Journal of Community Psychology, 46, 314-331. https://doi.org/10.1007/s10464-010-9346-5

Burns, B. J., Schoenwald, S. K., Burchard, J. D., Faw, L., \& Santos, A. B. (2000). Comprehensive community-based interventions for youth with severe emotional disorders: Multisystemic therapy and the wraparound process. Journal of Child and Family Studies, 9, 283-314. https://doi.org/10.1023/A:1026440406435

Carney, M. M., \& Buttell, F. (2003). Reducing juvenile recidivism: Evaluating the wraparound services model. Research on Social Work Practice, 13, 551-568. https://doi.org/10.1177/1049731503253364

Chitiyo, J. (2014). The wraparound process for youth with severe emotional behavioural disorders. Journal of Research in Special Education Needs, 14, 105-109. https://doi.org/10.1111/1471-3802.12008 
Clark, H. B., Lee, B. L., Prange, M. E., \& McDonald, M. A. (1996). Children lost within the foster care system: Can wraparound service strategies improve placement outcomes? Journal of Child and Family Studies, 5 , 39-54. https://doi.org/10.1007/BF02234677

Cleverly, K., Szatmari, P., Vaillancourt, T., Boyle, M., \& Lipman, E. (2012). Developmental trajectories of physical and indirect aggression from late childhood to adolescence: Sex differences and outcomes in emerging adulthood. Journal of the American Academy of Child \& Adolescent Psychiatry, 51, 1037-1051. https://doi.org/10.1016/j.jaac.2012.07.010

Cox, K. F. (2005). Examining the role of social network intervention as an integral component of community-based, family-focused practice. Journal of Child and Family Studies, 14, 443-454. https://doi.org/10.1007/s10826-005-6855-1

Cox, K., Baker, D., \& Wong, M. A. (2010). Wraparound retrospective: Factors predicting positive outcomes. Journal of Emotional and Behavioral Disorders, 18, 3-13. https://doi.org/10.1177/1063426609336955

Davis, M., \& Stoep, A. V. (1997). The transition to adulthood for youth who have serious emotional disturbance: Developmental transition and young adult outcomes. The Journal of Behavioral Health Services \& Research, 24, 400-427. https://doi.org/10.1007/BF02790503

Effland, V. S., Walton, B. A., \& McIntyre, J. S. (2011). Connecting the dots: Stages of implementation, wraparound fidelity and youth outcomes. Journal of Child and Family Studies, 20, 736-746. https://doi.org/10.1007/s10826-011-9541-5

Epstein, M. H. (2004). Behavioral and emotional rating scale: A strengths-based approach to assessment (2nd ed.). Austin, TX: PRO-Ed.

Epstein, M. H., Cullinan, D., Quinn, K. P., \& Cumblad, C. (1994). Characteristics of children with emotional and behavioral disorders in community-based programs designed to prevent placement in residential facilities. Journal of Emotional and Behavioral Disorders, 2, 51-57. https://doi.org/10.1177/106342669400200107

Erickson, C. D. (2011). Using systems of care to reduce incarceration of youth with serious mental illness. American Journal of Community Psychology, 49, 404-416. https://doi.org/10.1007/s10464-011-9484-4

Ernestus, S. M., \& Prelow, H. M. (2015). Patterns of risk and resilience in African-American and Latino youth. Journal of Community Psychology, 43, 954-972. https://doi.org/10.1002/jcop.21725

Fraser, M. W., Kirby, L. D., \& Smokowski, P. R. (2004). Risk and resilience in childhood. In M. W. Fraser (Ed.), Risk and resilience in childhood: An ecological perspective (pp. 13-66). Washington, DC: NASW Press.

Green, K. M., Zebrak, K. A., Robertson, J. A., Fothergill, K. E., \& Ensminger, M. E. (2012). Interrelationship of substance use and psychological distress over the life course among a cohort of urban African Americans. Drug and Alcohol Dependence, 123, 239-248. https://doi.org/10.1016/j.drugalcdep.2011.11.017

Greenbaum, P. E., Dedrick, R. F., Friedman, R. M., Kutash, K., Brown, E. C., Lardieri, S. P., \& Pugh, A. M. (1996). National Adolescent and Child Treatment Study (NACTS) outcomes for children with serious emotional and behavioral disturbance. Journal of Emotional and Behavioral Disorders, 4, 130-146. https://doi.org/10.1177/106342669600400301

Greenspoon, P. J., \& Saklofske, D. H. (2001). Toward an integration of subjective well-being and psychopathology. Social Indicators Research, 54, 81-108. https://doi.org/10.1023/A:1007219227883

Harris, P. A., Taylor, R., Thielke, R., Payne, J., Gonzalez, N., \& Conde, J. G. (2009). Research electronic data capture (REDCap) - A metadata-driven methodology and workflow process for providing translational research informatics support. Journal of Biomedical Informatics, 42, 377-381. https://doi.org/10.1016/j.jbi.2008.08.010

Hodges, K. (1990). Child and adolescent functional assessment scales. Nashville, TN: Vanderbilt Child Mental Health Services Evaluation Project.

Hodges, K., \& Wong, M. M. (1996). Psychometric characteristics of a multidimensional measure to assess impairment: The child and adolescent functional assessment scale. Journal of Child and Family Studies, 5, 445-467. https://doi.org/10.1007/BF02233865

Hodges, K., \& Wong, M. M. (1997). Use of the Child and Adolescent Functional Assessment Scale to predict service utilization and cost. Journal of Mental Health Administration, 24, 278-290. https://doi.org/10.1007/BF02832662 
Hodges, K., Xue, Y., \& Wotring, J. (2004). Use of the CAFAS to evaluate outcome for youths with severe emotional disturbance served by public mental health. Journal of Child and Family Studies, 13, 325-339. https://doi.org/10.1023/B:JCFS.0000022038.62940.a3

Illback, R. J., Nelson, C. M., \& Sanders, D. (1998). Community-based services in Kentucky: Description and 5 -year evaluation of Kentucky IMPACT. In M. H. Epstein, K. Kritash, \& A. Duchnowski (Eds.), Outcomes for children and youth with behavioral and emotional disorders and their families: Programs and evaluation best practices (pp. 141-172). Austin, TX: Pro-Ed.

Kerns, S. E. U., Pullmann, M. D., Putnam, B., Buher, A., Holland, S., Berliner, L., ... Trupin, E. W. (2014). Child welfare and mental health: Facilitators of and barriers to connecting children and youths in out-of-home care with effective mental health treatment. Children and Youth Services Review, 46, 315-324. https://doi.org/10.1016/j.childyouth.2014.09.013

Lyons, J. (2009). Communimetrics: A communication theory of measurement in human service settings. New York, NY: Springer. https://doi.org/10.1007/978-0-387-92822-7

McCammon, S. L. (2012). Systems of care as asset-building communities: Implementing strengths-based planning and positive youth development. American Journal of Community Psychology, 49, 556-565. https://doi.org/10.1007/s10464-012-9514-x

Monahan, K. C., Oesterle, S., Rhew, I., \& Hawkins, J. D. (2014). The relation between risk and protective factors for problem behaviors and depressive symptoms, antisocial behavior, and alcohol use in adolescence. Journal of Community Psychology, 42, 621-638. https://doi.org/10.1002/jcop.21642

Morrison, G. M., Brown, M., D’Incau, B., O’Farrell, S. L., \& Furlong, M. J. (2006). Understanding resilience in educational trajectories: Implications for protective possibilities. Psychology in the Schools, 43, 19-31. https://doi.org/10.1002/pits.20126

Myaard, M. J., Crawford, C., Jackson, M., \& Alessi, G. (2000). Applying behavior analysis within the wraparound process: A multiple baseline study. Journal of Emotional and Behavioral Disorders, 8, 216-229. https://doi.org/10.1177/106342660000800402

Painter, K. (2012). Outcomes for youth with severe emotional disturbance: A repeated measures longitudinal study of a wraparound approach of service delivery in systems of care. Child \& Youth Care Forum, 41, 407-425. https://doi.org/10.1007/s10566-011-9167-1

Pullmann, M. D., Kerbs, J., Koroloff, N., Veach-White, E., Gaylor, R., \& Sieler, D. (2006). Juvenile offenders with mental health needs: Reducing recidivism using wraparound. Crime \& Delinquency, 52, 375-397. https://doi.org/10.1177/0011128705278632

Shaffer, D., Gould, M. S., Brasic, J., Ambrosini, P., Fisher, P., Bird, H., \& Aluwahlia, S. (1983). A Children's Global Assessment Scale (CGAS). Archives of General Psychiatry, 40, 1228-1231. https://doi.org/10.1001/archpsyc.1983.01790100074010

Stambaugh, L. F., Mustillo, S. A., Burns, B. J., Stephens, R. L., Baxter, B., Edwards, D., \& DeKraai, M. (2007). Outcomes from wraparound and multisystemic therapy in a center for mental health services system-of-care demonstration site. Journal of Emotional and Behavioral Disorders, 15, 143-155. https://doi.org/10.1177/10634266070150030201

Suldo, S. M., \& Shaffer, E. J. (2008). Looking beyond psychopathology: The dual-factor model of mental health in youth. School Psychology Review, 37, 52-68.

Suter, J. C., \& Bruns, E. J. (2009). Effectiveness of the wraparound process for children with emotional and behavioral disorders: A meta-analysis. Clinical Child and Family Psychology Review, 12, 336-351. https://doi.org/10.1007/s10567-009-0059-y

Wagner, M., \& Newman, L. (2012). Longitudinal transition outcomes of youth with emotional disturbances. Psychiatric Rehabilitation Journal, 35, 199-208. https://doi.org/10.2975/35.3.2012.199.208

Walker, J. S. (2004). Team practices to increase individualization in wraparound. Focal Point, 18, 16-18.

Walker, J. S. (2008). How, and why, does wraparound work: A theory of change. In E. J. Bruns, \& J. S. Walker (Eds.), The resource guide to wraparound. Portland, OR: National Wraparound Initiative, Research and Training Center for Family Support and Children's Mental Health. 
Walker, J. S. (2015). A theory of change for positive developmental approaches to improving outcomes among emerging adults with serious mental health conditions. Journal of Behavioral Health Services \& Research, 42, 131-149. https://doi.org/10.1007/s11414-015-9455-x

Walker, J. S., \& Matarese, M. (2011). Using a theory of change to drive human resource development for wraparound. Journal of Child and Family Studies, 20, 791-803. https://doi.org/10.1007/s10826-011-9532-6

Walker, J. S., Bruns, E. J., \& The National Wraparound Initiative Advisory Group. (2008). Phases and activities of the wraparound process. In E. J. Bruns, \& J. S. Walker (Eds.), The resource guide to wraparound. Portland, OR: National Wraparound Initiative, Research and Training Center for Family Support and Children's Mental Health.

Weiner, D. A., Leon, S. C., \& Stiehl, M. J. (2011). Demographic, clinical, and geographic predictors of placement disruption among foster care youth receiving wraparound services. Journal of Child and Family Studies, 20, 758-770. https://doi.org/10.1007/s10826-011-9469-9

Wery, J. J., \& Cullinan, D. (2013). State definitions of emotional disturbance. Journal of Emotional and Behavioral Disorders, 21, 45-52. https://doi.org/10.1177/1063426611418234

Winters, N. C., \& Metz, W. P. (2009). The wraparound approach in systems of care. Psychiatric Clinics of North America, 32, 135-151. https://doi.org/10.1016/j.psc.2008.11.007

Wood, A. M., Linley, P. A., Maltby, J., Kashdan, T. B., \& Hurling, R. (2011). Using personal and psychological strengths leads to increases in well-being over time: A longitudinal study and the development of the strengths use questionnaire. Personality and Individual Differences, 50, 15-19. https://doi.org/10.1016/j.paid.2010.08.004

Wright, M. O., \& Masten, A. S. (2005). Resilience processes in development: Fostering positive adaptation in the context of adversity. In S. Goldstein, \& R. B. Brooks (Eds.), Handbook of resilience in children (pp. 17-37). New York, NY: Kluwer Academic/Plenum Publishers. https://doi.org/10.1007/0-306-48572-9_2

\section{Copyrights}

Copyright for this article is retained by the author(s), with first publication rights granted to the journal.

This is an open-access article distributed under the terms and conditions of the Creative Commons Attribution license (http://creativecommons.org/licenses/by/4.0/). 